\title{
EDITORIAL
}

\section{Dissemination science for prevention of adverse health outcomes from cannabis use}

\author{
Alexandre Paim Diaz, ${ }^{1}$ Antônio Geraldo da Silva ${ }^{2}$ iD \\ ${ }^{1}$ Núcleo de Psiquiatria, Universidade Federal de Santa Catarina (UFSC), Florianópolis, SC, Brazil. ${ }^{2}$ Faculdade de Medicina, Universidade do \\ Porto, Porto, Portugal.
}

According to data from the I Brazilian National Alcohol Survey (BNAS), conducted in 2010, the 12-month prevalence of cannabis use in Brazil was $2.1 \%$, with higher rates in individuals aged $14-30$ years (14-17 years: $2.1 \%$; 18-30 years: $4.4 \%) .^{1}$ In the United States, one study has shown that the prevalence of frequent use (defined as "six or more occasions of use in the past 30 days") among adolescents aged 16-18 has increased in the past three decades. ${ }^{2}$ In that study, Hamilton et al. reported period effects in frequent cannabis use 1.6 times greater in 2018 than in $2005 .^{2}$ The health consequences of cannabis use have been extensively described in the literature. Both heavy use and early age of onset are associated with grey-matter volume reduction in regions related to motivational and affective processing. ${ }^{3}$ In a systematic review, cannabis use in adolescence was associated with increased odds of depression and suicide attempt in young adulthood (OR $=1.37$ and $\mathrm{OR}=3.46$, respectively). ${ }^{4}$ The burden attributable to its use in terms of years of life lost to premature mortality or disability has been associated with risk of schizophrenia, lung cancer, and road traffic injuries among users. ${ }^{5}$

The already substantial and possibly rising prevalence of cannabis use, associated with its individual and social costs, especially among young people, means that dissemination of scientific evidence to prevent it and its negative outcomes is imperative. Dissemination science can be conceptualized as "the targeted distribution of information and intervention materials to a specific public health or clinical practice audience. The intent is to spread knowledge and associated evidence-based interventions." The present issue of the Brazilian Journal of Psychiatry brings an important article in which Fischer et al. present an evidence-based population health tool, the Low-Risk Cannabis Use Guidelines (LRCUG), for the prevention of adverse health outcomes among cannabis users. ${ }^{7}$ The 10 recommendations translated into Portuguese, based on systematic reviews and expert opinions, gather the best evidence regarding the negative effects of cannabis use and present them in a simple and accessible language for a broad audience. Categorization of these recommendations by grade of evidence also helps to communicate for which one the scientific literature is more consistent - for instance, the higher risks associated with early initiation, frequent or intensive cannabis use, and products with high THC content are graded as "substantial" evidence. For the first recommendation, however, the evidence grade is classified as "none required," perhaps due to its obviousness: "The most effective way to avoid any risks of cannabis use is to abstain from use."

There are several initiatives for the dissemination of scientific evidence in other fields, including physical activity, weight management, and alcohol and tobacco use. ${ }^{8}$ Challenges include how to evaluate the effectiveness of these recommendations, how best to deliver them for specific audiences, and how to ensure that scientific information is kept up to date. As Fischer et al. note, for international versions of existing instruments, it is also important to consider adaptations for the cultural, social, and epidemiological characteristics of different countries. In Brazil, where cannabis use for non-medical purposes remains illegal, although the behaviors and issues addressed in the LRCUG "may involve matters of illegality," as stated by the authors, the aim of preserving individual and public health makes these recommendations an important population health tool, especially for young people, who are most vulnerable to the negative consequences of cannabis use.

\section{Disclosure}

The authors report no conflicts of interest.

\section{References}

1 Jungerman FS, Menezes PR, Pinsky I, Zaleski M, Caetano R, Laranjeira R. Prevalence of cannabis use in Brazil: data from the I Brazilian National Alcohol Survey (BNAS). Addict Behav. 2010; 35:190-3.

2 Hamilton AD, Jang JB, Patrick ME, Schulenberg JE, Keyes KM. Age, period and cohort effects in frequent cannabis use among US students: 1991-2018. Addiction. 2019;114:1763-72.

3 Battistella G, Fornari E, Annoni JM, Chtioui H, Dao K, Fabritius M, et al. Long-term effects of cannabis on brain structure. Neuropsychopharmacology. 2014;39:2041-8.

4 Gobbi G, Atkin T, Zytynski T, Wang S, Askari S, Boruff J, et al. Association of cannabis use in adolescence and risk of depression,
Correspondence: Alexandre Paim Diaz, Núcleo de Psiquiatria, Universidade Federal de Santa Catarina, CEP 88040-970, Florianópolis, SC, Brazil.

E-mail: alexandrepaimdiaz@gmail.com
How to cite this article: Diaz AP, da Silva AG. Dissemination science for prevention of adverse health outcomes from cannabis use. Braz J Psychiatry. 2019;41:477-478. http://dx.doi.org/10.1590/ 1516-4446-2019-4109 
anxiety, and suicidality in young adulthood: a systematic review and meta-analysis. JAMA Psychiatry. 2019;76:426-34.

5 Imtiaz S, Shield KD, Roerecke M, Cheng J, Popova S, Kurdyak P, et al. The burden of disease attributable to cannabis use in Canada in 2012. Addiction. 2016;111:653-62.

6 Glasgow RE, Vinson C, Chambers D, Khoury MJ, Kaplan RM, Hunter C. National Institutes of Health approaches to dissemination and implementation science: current and future directions. Am J Public Health. 2012;102:1274-81.
7 Fischer B, Malta M, Messas G, Ribeiro M. Introducing the evidencebased population health tool of the lower-risk cannabis use guidelines to Brazil. Braz J Psychiatry. 2019;41:550-5.

8 National Institute of Health Office of Disease Prevention. NIH Public Health Campaigns: National Institute of Health [Internet]. 2019 [cited 2019]. prevention.nih.gov/research-priorities/dissemina tion-implementation/nih-public-health-campaigns 